\title{
An Improved Predictive Model for Determining the Permeability Coefficient of Artificial Clayey Soil Based on Double $T_{2}$ Cut-Offs
}

\author{
Zhen Lu $\mathbb{D}^{1,}{ }^{1,2}$ Aimin Sha $\mathbb{D}^{1,2}$ Junfeng Gao $\mathbb{D}^{1,2}$ Meng Jia, ${ }^{1,2}$ and Wentong Wang $\mathbb{D}^{1,2}$ \\ ${ }^{1}$ Key Laboratory for Special Area Highway Engineering of Ministry of Education, Chang'an University, \\ Xi'an, Shaanxi 710064, China \\ ${ }^{2}$ School of Highway, Chang'an University, Xi'an, Shaanxi 710064, China \\ Correspondence should be addressed to Aimin Sha; ams@chd.edu.cn
}

Received 8 August 2020; Revised 22 November 2020; Accepted 30 November 2020; Published 10 December 2020

Academic Editor: Jianxi Zhu

Copyright ( $\odot 2020$ Zhen Lu et al. This is an open access article distributed under the Creative Commons Attribution License, which permits unrestricted use, distribution, and reproduction in any medium, provided the original work is properly cited.

\begin{abstract}
Permeability is one of the most important engineering properties of clayey soil. However, the traditional method for determining the permeability coefficient is time-consuming. To establish a simple and accurate predictive method to obtain the permeability coefficient of artificial clayey soil based on the double cut-off transverse relaxation times ( $T_{2}$ cut-offs) using low-field nuclear magnetic resonance (NMR) technology, eight kinds of artificial clayey soil with different mineralogical compositions were prepared in the laboratory. Evaporation tests at $40^{\circ} \mathrm{C}$ were carried out on the saturated artificial clayey soil samples in an oven. During the evaporation process, NMR tests were also performed on the artificial clayey soil every hour. The results showed that the evaporation process could be divided into three stages according to different evaporation rates: the constant rate stage (CRS), the falling rate stage (FRS), and the residual stage (RS). The water evaporated in the CRS and FRS was defined as the absolute movable water and the partially movable water, respectively. The water that could not evaporate in the RS was defined as the immovable water. Based on the cumulative signal amplitudes in the $T_{2}$ spectrum corresponding to different kinds of water, the double $T_{2}$ cutoffs were defined. On the basis of the double $T_{2}$ cut-offs and $T_{2}$ spectrum of the saturated sample, an improved Timur-Coates (TC) model was established. The prediction capability of the improved model was evaluated by finding the determination coefficient $\left(R^{2}\right)$, mean absolute error (MAE), and root-mean-square error (RMSE). Compared with the typical TC model, the prediction accuracy of the improved model was much higher. In addition, the relationships between the double $T_{2}$ cut-offs and fractal dimension $(D)$ of the $T_{2}$ spectrum of saturated artificial clayey soil were also identified.
\end{abstract}

\section{Introduction}

In recent years, artificial clayey soil has been widely used in various engineering constructions $[1,2]$. As one of the most important engineering parameters, the permeability coefficient is closely related to the consolidation deformation of soil, seepage of groundwater, and diffusion of pollutants in environmental soil [1-3]. The permeability coefficient of artificial clayey soil needs to be determined before the design and construction of civil engineering, highway engineering, dam engineering, and refuse treatment engineering projects. The most commonly used method for measuring the permeability coefficient of an artificial clayey soil is variable head permeability testing. However, variable head permeability testing is time- and effort-consuming [4]. Many previous studies have proposed models for predicting the permeability coefficient of clayey soil [1, 3-9]. However, these models need other parameters which are hard to obtain, and the errors between the measured and predicted values of permeability coefficients cannot be ignored. Therefore, it is necessary to build a simple and accurate predictive model.

In recent years, low-field NMR has been widely used to characterize the pore size distributions of porous media such as coal, shale, soil, and sandstone based on the $T_{2}$ spectra [10-13]. Based on the pore size distributions of porous media, many studies have been performed to predict the permeability of these porous media. Yao et al. established a permeability model for coal from the Schlumberger Doll Research (SDR) equation and Timur-Coates (TC) equation 
by using NMR relaxometry [14]. Further, Li et al. classified the pore types of shale using the $T_{2}$ spectrum and proposed a permeability model for shale based on the regional TC model [15]. Rezaee et al. also developed a predictive model for sandstone on the basis of the NMR parameters from the $T_{2}$ spectrum [16]. However, few studies have focused on predictive models based on NMR for clayey soil. Therefore, to simplify the determination of the permeability coefficient of clayey soil, we previously proposed a novel method for predicting the permeability coefficients of artificial clayey soil based on the TC model by using low-field NMR [17]. This novel method was proved to have sufficient prediction capability. In this previous study [17], the water in the soil was classified into two kinds: free water and bound water. Based on this classification, a TC model for artificial clayey soil was proposed. The TC model was also called the free fluid model. In theory, the greater the detail in which the water in artificial clayey soil is classified, the higher the prediction accuracy of the model.

On the basis of our previous study [17], we continued to research on this prediction. The aim of this paper was to establish an improved model for predicting the permeability coefficients of clayey soil. Instead of the classification of water used in the previous study, the water in artificial clayey soil was divided into three kinds-absolute movable water, partially movable water, and immovable water-in this study. Based on this novel classification, an improved TC model was developed. The determination coefficient $\left(R^{2}\right)$, mean absolute error (MAE), and root-mean-square error (RMSE) were used to evaluate the prediction accuracy of the improved model. Compared with the model proposed in our previous study, the prediction reliability of the novel model is better. The double $T_{2}$ cut-offs were defined to distinguish cumulative signal amplitudes in the $T_{2}$ spectrum corresponding to the weights of different kinds of water in artificial clayey soil. Similar to our previous study, the relationships between the double $T_{2}$ cut-offs and fractal dimension $(D)$ were also established to remove evaporation testing from the determination process of the permeability coefficient. Using this method, the permeability coefficient of artificial clayey soil can be determined simply, quickly, and accurately.

\section{Materials and Methods}

2.1. Materials. Two clay mineral (montmorillonite and kaolinite) powders and one sand powder were used in this study to prepare artificial clayey soil. The sand powder was purchased from Guangzhou Jialiang Mineral Products Co., Ltd. (Guangzhou, China). The montmorillonite and kaolinite powders were provided by Inner Mongolia Ningcheng Tianyu Chemical Co., Ltd. (Chifeng, China) and Guangzhou Yifeng Chemical Technology Co., Ltd. (Guangzhou, China), respectively. A Mastersizer 2000 laser particle analyzer was used to determine the grain size distributions of these three mineral powders in this study. The grain size distributions are depicted in Figure 1. The Atterberg limits, specific gravity values, and classifications of the three kinds of powders were determined following the methods in ASTM D4318, ASTM
D2487, and ASTM D2478, respectively. The X-ray fluorescence was also used to determine the chemical compositions of the powders. The basic properties of the three powders, including their Atterberg limits, specific gravity, and chemical composition, are summarized in Table 1.

\subsection{Methods}

2.2.1. NMR Theory. As a nondestructive, fast, and accurate testing technology, nuclear magnetic resonance technology is widely used to evaluate the pore characteristics of porous media $[10,12]$. The NMR theory is briefly summarized as follows.

NMR relaxation consists of three parts: bulk relaxation, diffusion relaxation, and surface relaxation. The relaxation time can be divided into two categories: longitudinal relaxation time $\left(T_{1}\right)$ and transverse relaxation time $\left(T_{2}\right)$. The transverse relaxation time is more often used because it is shorter than the longitudinal relaxation time and easier to measure using an NMR analyzer [18]. The transverse relaxation time can be calculated by the following equation $[10,19-21]$ :

$$
\frac{1}{T_{2}}=\frac{1}{T_{2 B}}+\frac{1}{T_{2 D}}+\frac{1}{T_{2 S}},
$$

where $T_{2 B}$ is the transverse bulk relaxation time, $T_{2 D}$ is the transverse diffusion relaxation time, and $T_{2 S}$ is the transverse surface relaxation time.

T2D can be calculated by the following [22]:

$$
\frac{1}{T_{2 D}}=\frac{C_{d}\left(\gamma G T_{E}\right)^{2}}{12}
$$

where $C_{d}$ is the diffusion coefficient of the fluid in the pores, $G$ is the gradient magnetic field intensity, and $T_{E}$ is the echo interval time. When the magnetic field is uniform, $G$ equals 0 .

$\mathrm{T} 2 \mathrm{~S}$ can be calculated by the following equation [23]:

$$
\frac{1}{T_{2 S}}=\rho_{2}\left(\frac{S}{V}\right)_{\text {pore }},
$$

where $S$ is the surface area of the pore, $V$ is the volume of the pore, and $\rho_{2}$ is the surface relaxivity of the pore surface. The surface relaxivity is mainly affected by the physicochemical properties of the soil particle surface [24].

The relationship between the surface area of the pore, the volume of the pore, and the diameter of the pore can be expressed by the following equation:

$$
\frac{S}{V}=\frac{F_{s}}{r},
$$

where $r$ is the diameter of the pore and $F_{s}$ is the shape factor of the pore. For planar, columnar, and spherical pores, $F_{s}$ is equal to 1,2 , and 3 , respectively.

Equation (4) can be converted into

$$
\frac{1}{T_{2 S}}=\rho_{2} \frac{F_{s}}{r} \text {. }
$$

When the magnetic field is uniform, $G$ equals 0 , so $1 / T_{2 D}$ equals 0 . When the liquid in the pore is distilled water, $T_{2 B}$ is 


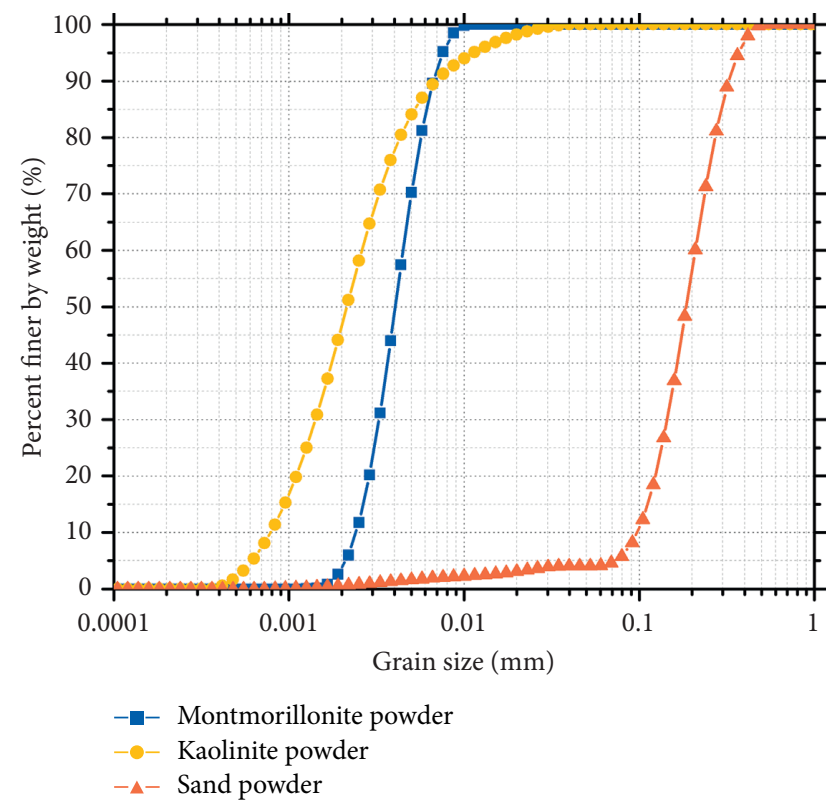

FIGURE 1: The grain size distributions of the sand, kaolinite, and montmorillonite powders.

TABLE 1: Basic properties of the three mineral powders used in this study.

\begin{tabular}{|c|c|c|c|}
\hline \multirow{2}{*}{ Property } & \multicolumn{3}{|c|}{ Materials } \\
\hline & Sand & Kaolinite & Montmorillonite \\
\hline \multicolumn{4}{|l|}{ Atterberg limits } \\
\hline Plastic limit (\%) & - & 32.00 & 61.34 \\
\hline Liquid limit (\%) & - & 68.99 & 178.65 \\
\hline Plasticity index & - & 36.99 & 117.31 \\
\hline \multicolumn{4}{|l|}{ Grain size distribution } \\
\hline Clay $(\% ;<0.005 \mathrm{~mm})$ & 1.63 & 70.23 & 84.1 \\
\hline $\begin{array}{l}\text { Silt (\%; } \\
0.005 \mathrm{~mm}-0.075 \mathrm{~mm})\end{array}$ & 4.15 & 29.77 & 15.9 \\
\hline Sand $(\% ;>0.075 \mathrm{~mm})$ & 94.22 & 0 & 0 \\
\hline \multicolumn{4}{|l|}{ Chemical composition } \\
\hline $\mathrm{SiO}_{2}(\%)$ & 98.85 & 57.82 & 66.63 \\
\hline $\mathrm{Al}_{2} \mathrm{O}_{3}(\%)$ & 0.57 & 35.24 & 16.07 \\
\hline $\mathrm{K}_{2} \mathrm{O}(\%)$ & - & 3.89 & - \\
\hline $\mathrm{Fe}_{2} \mathrm{O}_{3}(\%)$ & 0.08 & 1.86 & 6.50 \\
\hline $\mathrm{CaO}(\%)$ & 0.18 & - & 3.99 \\
\hline $\mathrm{MgO}(\%)$ & - & 0.37 & 5.32 \\
\hline Specific gravity & 2.68 & 2.76 & 2.61 \\
\hline Classification & - & $\mathrm{CH}$ & $\mathrm{CH}$ \\
\hline
\end{tabular}

much larger than $T_{2 S}$, so $1 / T_{2 B}$ can also be considered negligible [25]. Equation (1) can then be simplified into the following equation:

$$
\frac{1}{T_{2}} \approx \frac{1}{T_{2 S}}=\rho_{2} \frac{F_{s}}{r} .
$$

From the previous equation, there is a linear relationship between $T_{2}$ and $r$. The quantity of pores with a specific pore size can then be obtained from the $T_{2}$ spectra of watersaturated samples. A small $T_{2}$ corresponds to a small pore and a large $T_{2}$ corresponds to a large pore [26].
2.2.2. Sample Preparation. Eight artificial clayey soil samples were prepared in the laboratory. All the samples consisted of clay mineral (montmorillonite or kaolinite) and sand. Four samples consisted of montmorillonite and sand, while the other four consisted of kaolinite and sand. These two groups were named the M-group and $\mathrm{K}$-group, respectively. The clay mineral (montmorillonite or kaolinite) contents in each group were increased from $40 \%$ to $100 \%$ at intervals of $20 \%$. The eight artificial clayey soil samples were named after the clay mineral content and clay mineral type. For example, M80 consisted of montmorillonite and sand, and the clay mineral content was $80 \%$.

All eight artificial clayey soils were prepared under laboratory conditions. The process of sample preparation is briefly summarized as follows. The mineral powders were oven-dried at $250^{\circ} \mathrm{C}$ for 24 hours to a constant weight. At $250^{\circ} \mathrm{C}$, almost all of the water in the artificial clayey soil was removed and the structure of the clay particles was unaffected [27-30]. Next, the clay mineral powder and sand powder in a dry state were thoroughly mixed at fixed proportions. Then, distilled water was added to the mixtures until the water content reached the plastic limit. To make the mixtures reach a full hydration state, the mixtures were stirred using a mortar-mixing apparatus at 60 rounds/min for $5 \mathrm{~min}$ and put into self-sealing plastic bags for two days. Following the hydration period, the mixtures were shaped in a hollow cylinder with an inner diameter and height of $31.9 \mathrm{~mm}$ and $80 \mathrm{~mm}$, respectively, using a Jack under static pressure to reach the fixed dry density. Finally, the eight artificial clayey soil samples were saturated by the vacuum saturation method.

2.2.3. NMR and Evaporation Tests. A MesoMR12-150H-I NMR analyzer (NIUMAG Co., Ltd., Suzhou, China), shown in Figure 2, was used for NMR tests. The composition of the instrument used in this study was the same as that used in a previous study [21]. The parameters of the NMR tests in this study are shown in Table 2. The pulse sequence of the NMR tests used in this study was the Carr-Purcell-Meiboom-Gill (CPMG) pulse sequence [31]. Because of magnetic field inhomogeneities, the value of $T_{2}$ measured by a free induction decay (FID) pulse sequence is less than the actual value [10]. The CPMG pulse sequence selected in this study was the same as that in previous studies [20,23, 26, 32]. The $T_{2}$ spectra were obtained automatically using the software installed on the NMR analyzer. Inversion software was developed based on inverse Laplace transform [33] and the simultaneous iterative reconstruction technique (SIRT) [34].

The NMR tests were first performed on the eight saturated samples and then carried out on the evaporated samples every hour until the $T_{2}$ spectrum did not change. The samples were evaporated in an oven, with the drying temperature set to $40^{\circ} \mathrm{C}$ to simulate the highest temperature of the subgrade under natural conditions. It is noted that the temperature of the sample has dramatic effects on the $T_{2}$ spectrum. The temperature of the sample needs to be equal to the temperature of the magnetic field $\left(30^{\circ} \mathrm{C}\right)$. So, after the sample was taken out from the oven and before each NMR 


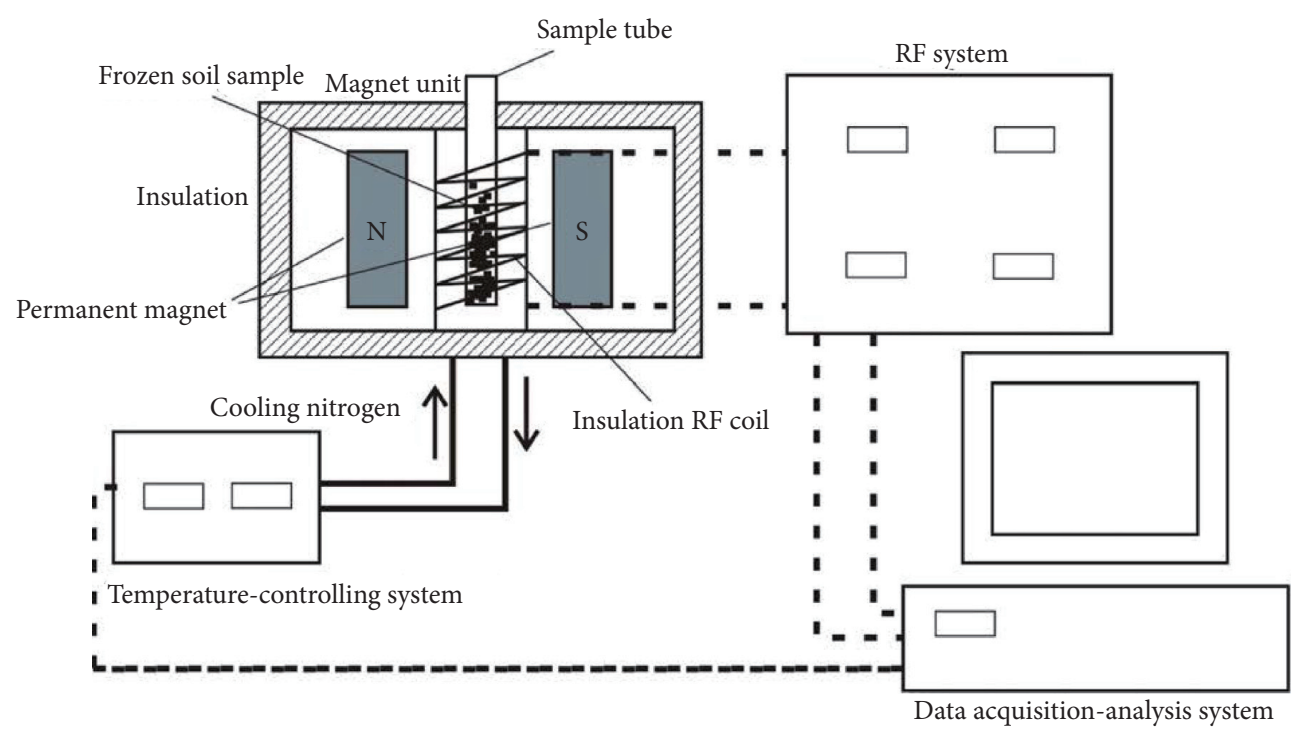

FIgure 2: Composition of the MesoMR12-150H-I NMR analyzer [21].

TABle 2: Parameters of the NMR tests.

\begin{tabular}{lcc}
\hline Parameter & Value & Unit \\
\hline Magnetic induction intensity & 0.55 & $\mathrm{~T}$ \\
Frequency & 13 & $\mathrm{MHz}$ \\
Coil diameter & 60 & $\mathrm{~mm}$ \\
Ambient temperature & 30 & ${ }^{\circ} \mathrm{C}$ \\
$90^{\circ}$ pulse width & 20 & $\mu \mathrm{s}$ \\
$180^{\circ}$ pulse width & 30.48 & $\mu \mathrm{s}$ \\
Sampling points & 208018 & - \\
Sampling frequency & 200 & $\mathrm{kHz}$ \\
Frequency delay & 8 & $\mu \mathrm{s}$ \\
Latency time of repeated sampling & 8000 & $\mathrm{~ms}$ \\
Analog gain & 20 & - \\
Digital gain & 3 & - \\
Accumulated sampling number & 4 & - \\
Echo time & 260 & $\mu \mathrm{s}$ \\
Echo number & 4000 & - \\
\hline
\end{tabular}

test, the sample needed to be cooled to $30^{\circ} \mathrm{C}$. During the cooling process, the sample was wrapped in plastic wrap to prevent further dehydration.

\section{Results and Discussion}

3.1. Morphology of $\mathrm{T}_{2}$ Spectra during the Evaporation Process. The variations of the $T_{2}$ spectra during the evaporation process of artificial clayey soils consisting of different clay minerals (kaolinite and montmorillonite) and sand are presented in Figure 3. All the $T_{2}$ spectra in Figure 3 are unimodal, which suggests that the pores in both saturated and evaporated samples were distributed uniformly and continuously $[15,35]$. The $T_{2}$ spectra of artificial clayey soil in the initial state shifted to the left with increasing clay content. According to equation (6), this might be because the relaxation coefficient increased or the pore diameter decreased with increasing clay content in the artificial clayey soil. All of the $T_{2}$ spectra of the eight artificial clayey soils shifted to the left with increasing evaporation time.
According to NMR theory, the pore size is proportional to $T_{2}$, so this means that the pore size kept decreasing during the evaporation process. This indicates that decreases in the pore size may be the reason for clayey soil shrinkage during evaporation [36].

According to our previous study [17], the weight of distilled water $(m)$ in artificial clayey soil is proportional to the $T_{2}$ total signal amplitude $\left(A_{t}\right)$, which is equal to the total area under the $T_{2}$ spectrum curve. The relationship between $A_{t}$ and $m$ can be expressed by equation (7); the $R^{2}$ value of equation (7) was 0.996, as shown in Figure 4. This indicated that the weight of evaporated water can be expressed by the attenuated cumulative $T_{2}$ signal amplitudes:

$$
A_{t}=302.6 \mathrm{~m} \text {. }
$$

The variation of the total $T_{2}$ signal amplitude with respect to evaporation time is shown in Figure 5. During evaporation, $A_{t}$ kept decreasing, while the decay rate was different at various evaporation times. The decay rate of $A_{t}$ was defined as $R_{t}$, which can be calculated by the following equation:

$$
R_{t}=\frac{\Delta A_{t}}{t}
$$

where $\Delta A_{t}$ is the attenuated $A_{t}$ during evaporation time $t$.

The $R_{t}$ values for each hour during evaporation were calculated and are presented in Figure 6. From Figure 6, it can be seen that $R_{t}$ was approximately constant firstly and then decreased to 0 . According to the $R_{t}$ values, the evaporation process can be divided into three stages: the constant rate stage (CRS), the falling rate stage (FRS), and the residual stage (RS). The demarcation points of the three stages were defined as $T_{f}$ and $T_{r}$. The demarcation point of CRS and FRS is $T_{f}$, and the demarcation point of FRS and RS is $T_{r}$. The $T_{f}$ values of artificial clayey soils which consisted of the same clay mineral were found to be the same. The $T_{f}$ value of artificial clayey soil consisting of kaolinite and sand was $20 \mathrm{~h}$, 


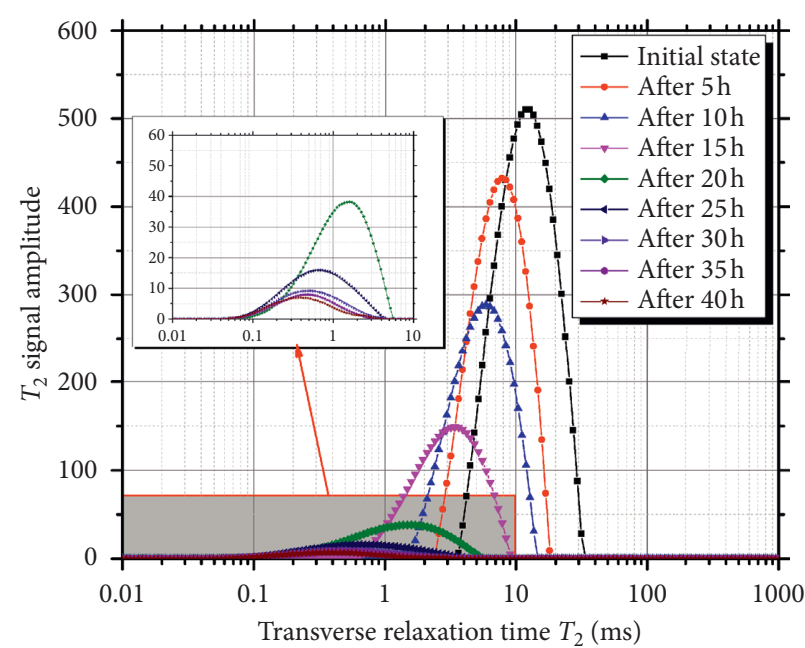

(a)

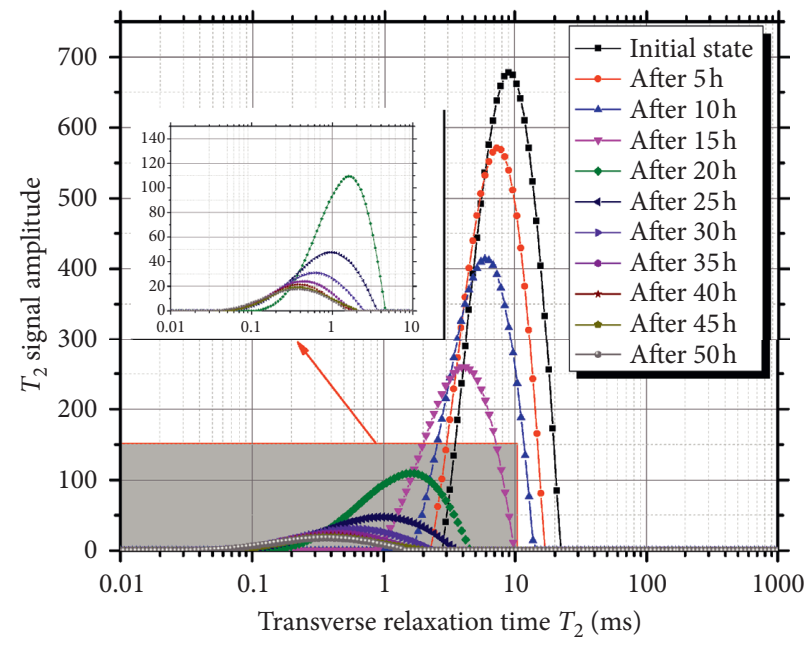

(c)

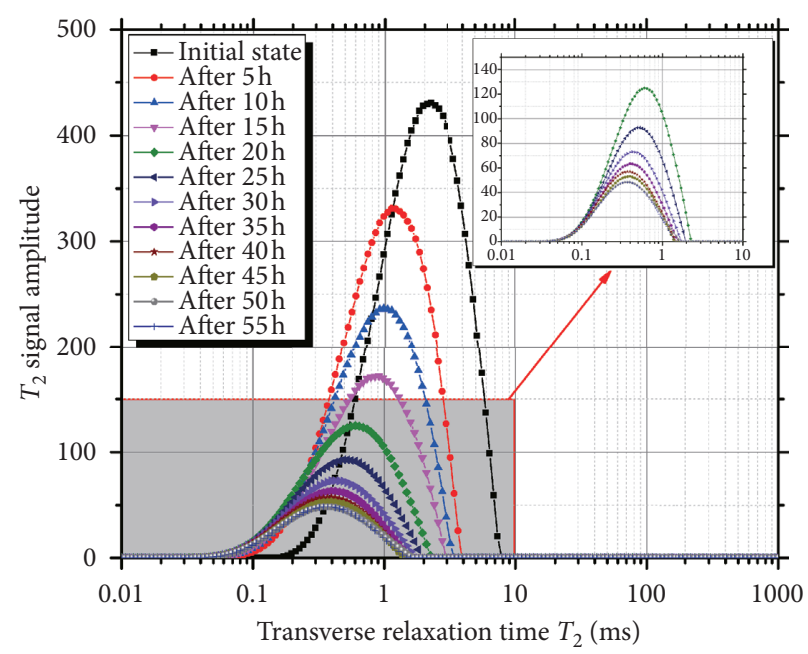

(e)

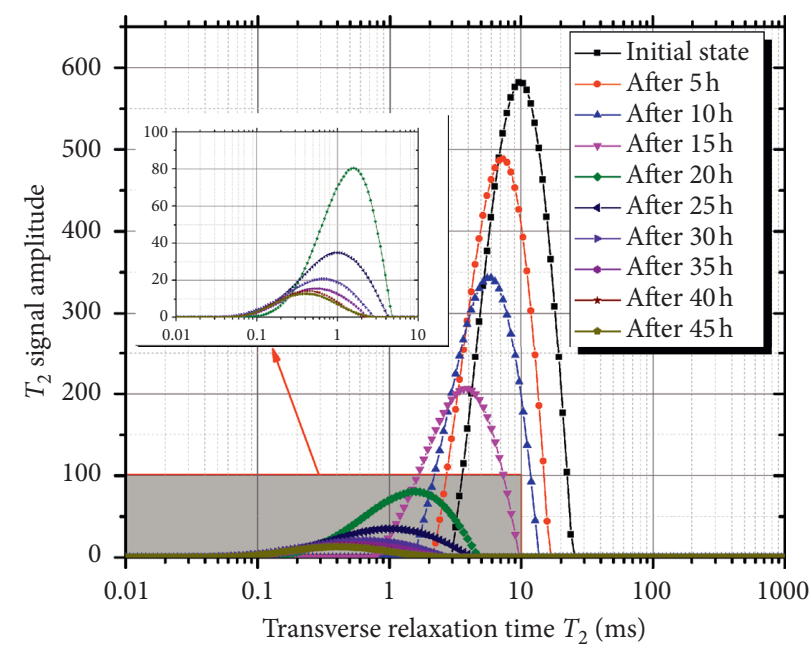

(b)

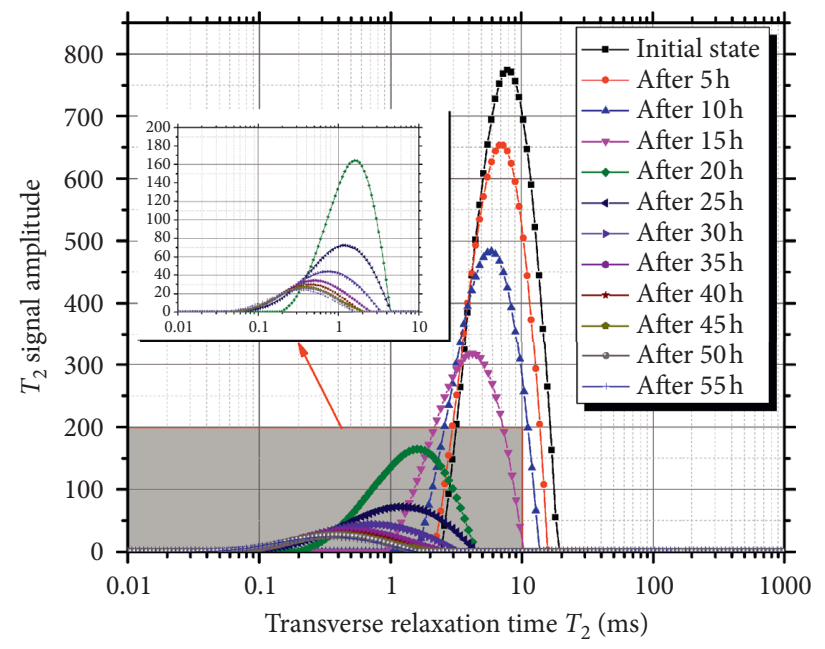

(d)

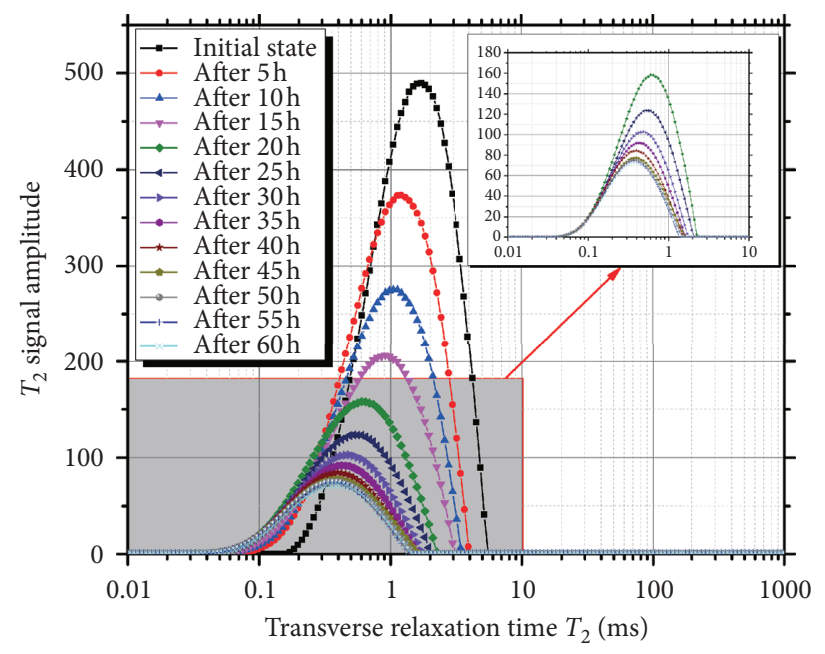

(f)

Figure 3: Continued. 


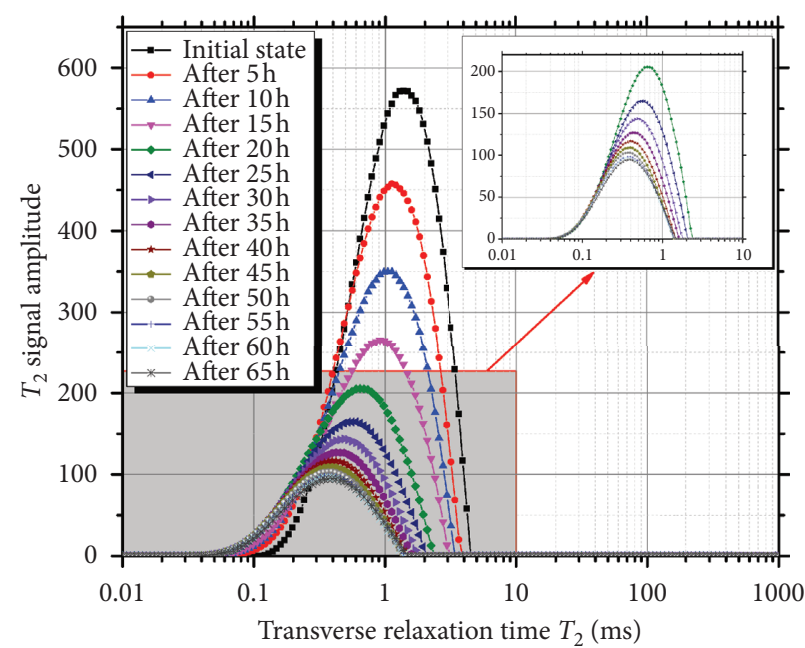

(g)

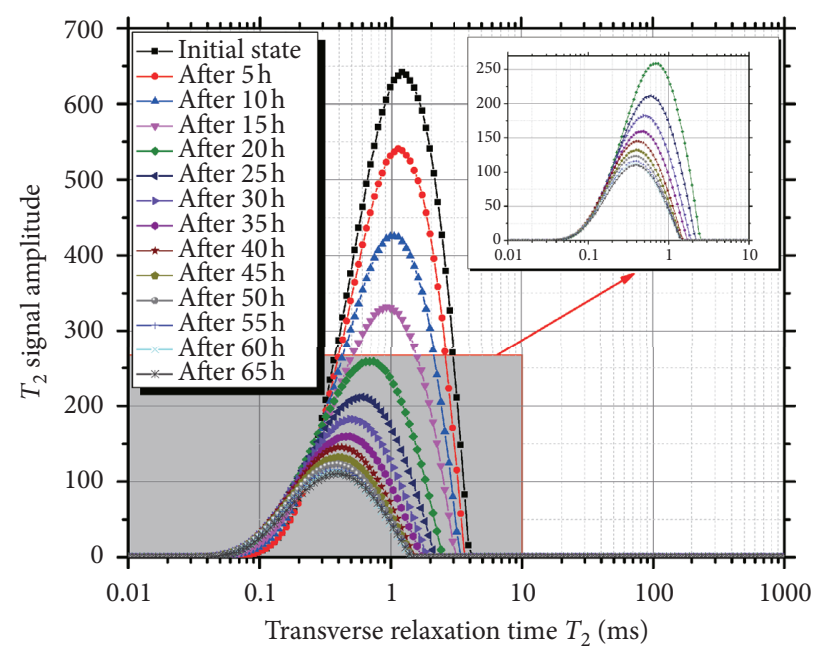

(h)

FiguRE 3: The variations of the $T_{2}$ spectra of artificial clayey soils during evaporation: (a) K40; (b) K60; (c) K80; (d) K100; (e) M40; (f) M60; (g) M80; (h) M100.

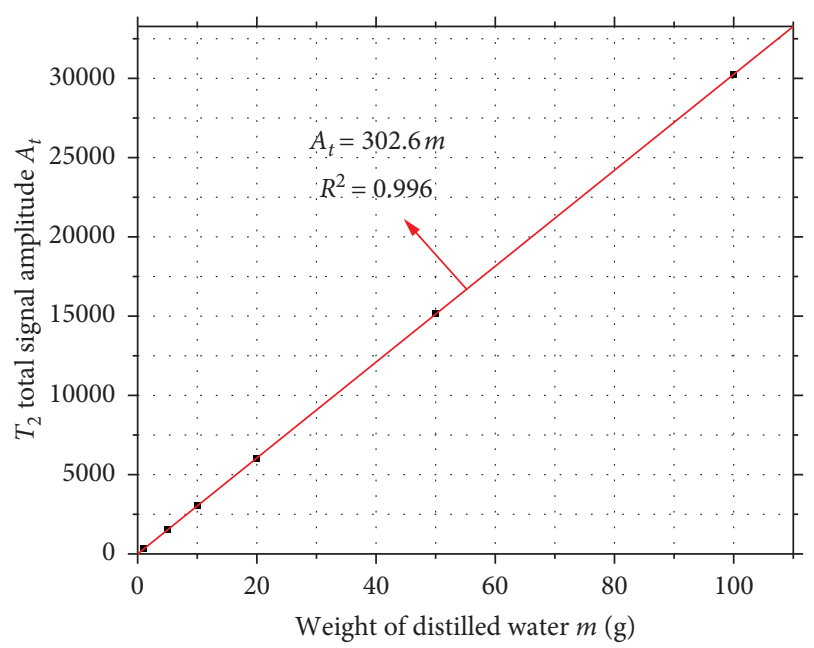

FIGURE 4: Relationship between the weight of distilled water in artificial clayey soil and the $T_{2}$ total signal amplitude.

while the $T_{f}$ value of artificial clayey soil consisting of montmorillonite and sand was $6 \mathrm{~h}$. The results indicated that the $T_{r}$ values of artificial clayey soils with different clay mineral types and contents varied greatly.

\subsection{The Improved TC Permeability Prediction Model. The} two most commonly used permeability prediction models of porous media based on NMR technology are the SDR model and the TC model. According to our previous study [17], the SDR model was not suitable for predicting the permeability coefficients of clayey soils that consist of different minerals. This can be explained by the fact that the relaxation coefficients of clayey soils with different mineralogical compositions vary greatly. The geometric mean transverse relaxation time $\left(T_{2 g m}\right)$ of clayey soils with different mineralogical compositions cannot be used to compare the average pore size directly.

The TC model can be described by the following equation:

$$
k_{\mathrm{TC}}=a \varphi_{\mathrm{NMR}}^{m}\left(\frac{\mathrm{FFV}}{\mathrm{BFV}}\right)^{n},
$$

where FFV and BFV are the volumes of free fluid and bound fluid, respectively, in a porous medium. The three empirical constants $(a, m, n)$ are related to the properties of porous media. $\varphi_{\mathrm{NMR}}$ is the total porosity of artificial clayey soil as measured by NMR tests. For saturated artificial clayey soil, $\varphi_{\mathrm{NMR}}$ can be determined by the following equation:

$$
\varphi_{\mathrm{NMR}}=\frac{A_{t}}{302.6 \rho_{w} V}
$$

where $\rho_{w}$ is the density of distilled water and $V$ is the volume of artificial clayey soil.

In our previous study [17], it was proved that the TC model can be used to determine the permeability coefficient of artificial clayey soil. In addition, the TC model is also called the free fluid model. The key to determining the permeability coefficient via the TC model is to calculate the volumes of two kinds of fluids (FFV and BFV) accurately. The FFV and BFV were defined as the water evaporated in the constant and other rate stages, respectively. However, it is more reasonable to divide the evaporation process into three stages according to Figure 6. This is because the greater the detail in which the water is classified, the higher the prediction accuracy of the model. In this study, the water evaporated in the CRS and FRS was defined as the absolute movable water and the partially movable water, respectively. The water that could not evaporate in the RS was defined as the immovable water. According to NMR theory, the weights of water evaporated in different stages correspond to different parts of the cumulative signal amplitudes in the $T_{2}$ 


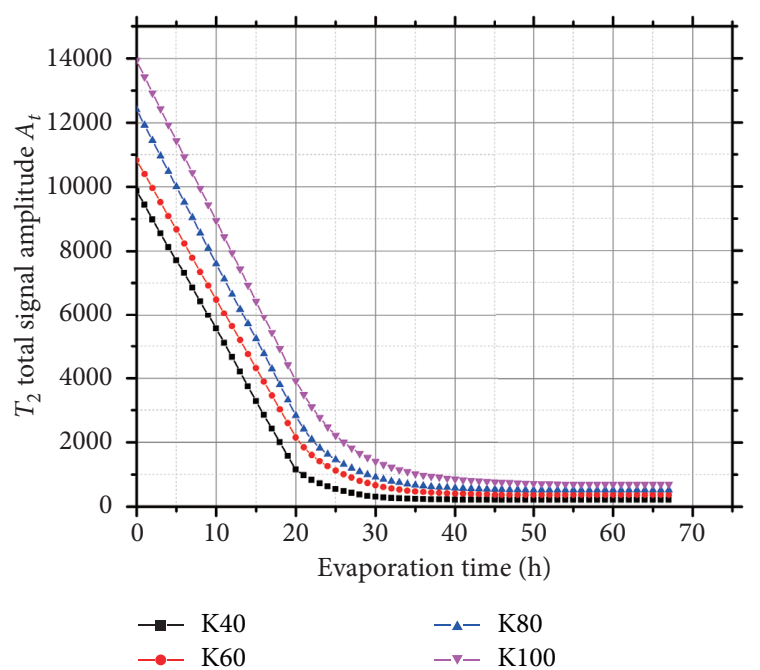

(a)

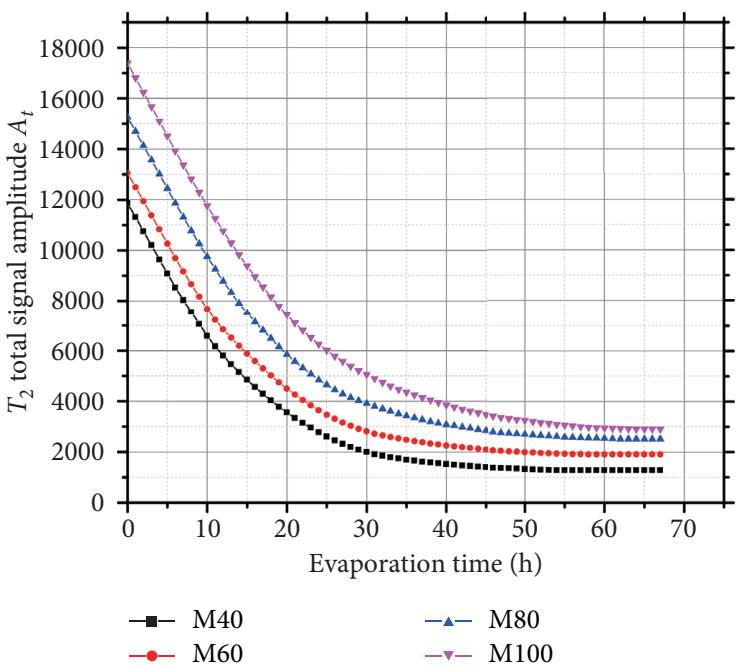

(b)

Figure 5: Variation of the total $T_{2}$ signal amplitude with respect to evaporation time: (a) K-group and (b) M-group.

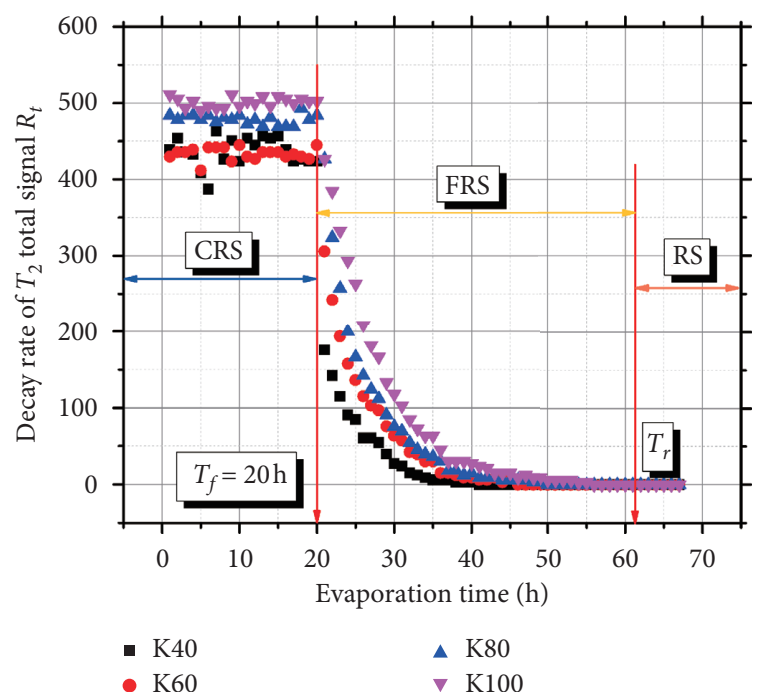

(a)

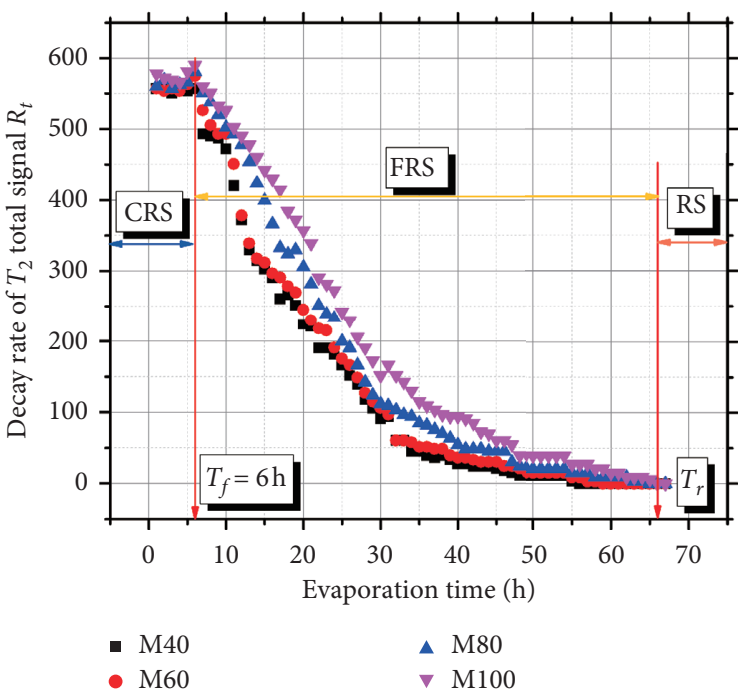

(b)

Figure 6: The decay rate of the $T_{2}$ total signal versus evaporation time: (a) K-group and (b) M-group.

spectra of saturated artificial clayey soils. The $T_{2}$ cut-off was used to discriminate the cumulative signal amplitudes corresponding to the different kinds of water. In this study, double $T_{2}$ cut-offs $\left(T_{2 c f}\right.$ and $\left.T_{2 c r}\right)$ were defined to discriminate the three kinds of water. As shown in Figure 7, the cumulative signal amplitudes between $T_{2 \min }$ and $T_{2 c r}\left(A_{\text {imw }}\right)$ correspond to the immovable water. Similarly, the cumulative signal amplitudes between $T_{2 c r}$ and $T_{2 c f}\left(A_{\mathrm{pmw}}\right)$ correspond to the partially movable water, and the cumulative signal amplitudes between $T_{2 c f}$ and $T_{2 \max }$ correspond to the absolute movable water $\left(A_{\mathrm{amw}}\right) . A_{t}, \varphi_{\mathrm{NMR}}, A_{\mathrm{imw}}, A_{\mathrm{pmw}}$, and $A_{\mathrm{amw}}$ values of the eight artificial clayey soils are summarized in Table 3.

To establish the improved TC permeability coefficient prediction model, the permeability coefficients $\left(K_{\mathrm{TC}}\right)$ of the eight artificial clayey soils were also measured by variable head permeability tests. It is noted that the permeability coefficients are not the same as the permeability $\left(k_{\mathrm{TC}}\right)$ in the TC model. According to previous studies [17, 37], $K_{\mathrm{TC}}$ is proportional to $k_{\mathrm{TC}}$. The TC model can thus be converted into the following equation:

$$
K_{\mathrm{TC}}=b \cdot k_{\mathrm{TC}}=b \cdot a \varphi_{\mathrm{NMR}}^{m}\left(\frac{\mathrm{FFV}}{\mathrm{BFV}}\right)^{n}=B \varphi_{\mathrm{NMR}}^{m}\left(\frac{\mathrm{FFV}}{\mathrm{BFV}}\right)^{n} .
$$

From the previous equation, there are relationships between $K_{\mathrm{TC}}$ and $\varphi_{\mathrm{NMR}}$ and the volume ratios of different kinds of water. The relationships between $K_{\mathrm{TC}}$ and $\varphi_{\mathrm{NMR}}$, $A_{\mathrm{pmw}} / A_{\mathrm{amw}}$, and $A_{\mathrm{imw}} / A_{\mathrm{amw}}$ are shown in Figure 8. As presented in Figure $8, K_{\mathrm{TC}}$ decreased with increasing $A_{\mathrm{pmw}} /$ $A_{\text {amw }}$ and $A_{\text {imw }} / A_{\text {amw }}$. It is noted that $K_{\mathrm{TC}}$ decreased with 


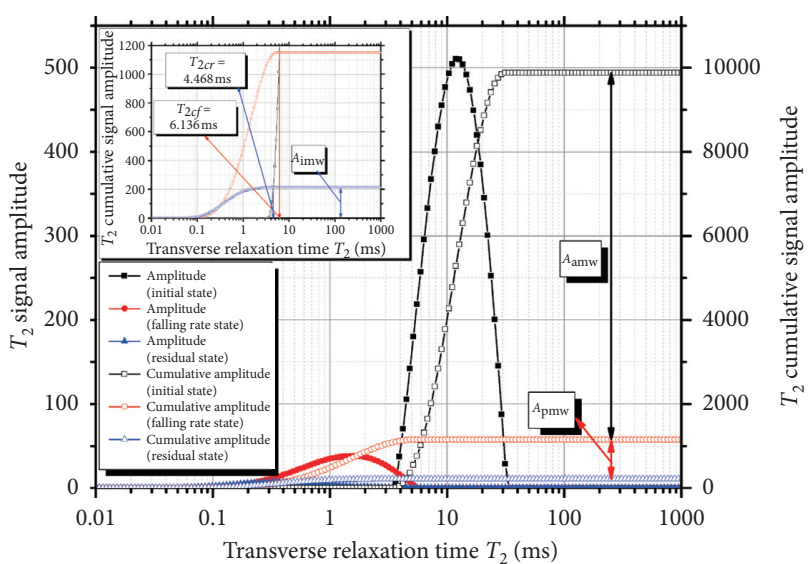

(a)

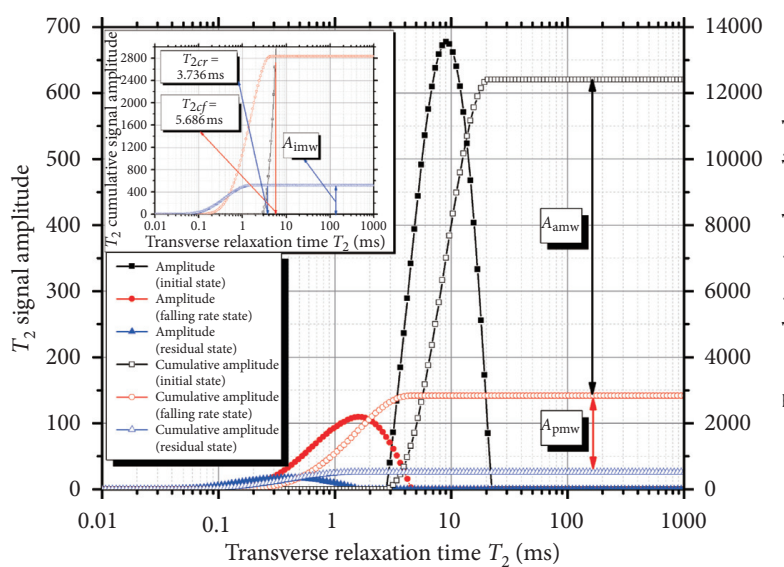

(c)

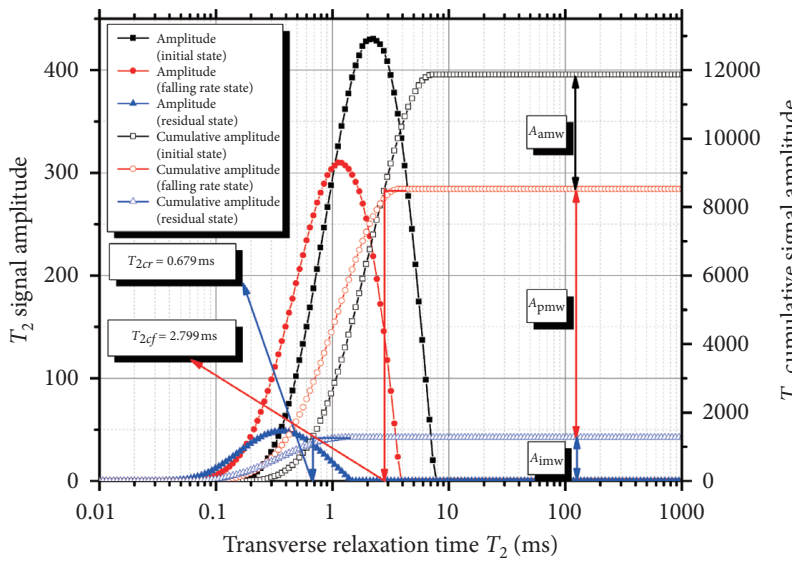

(e)

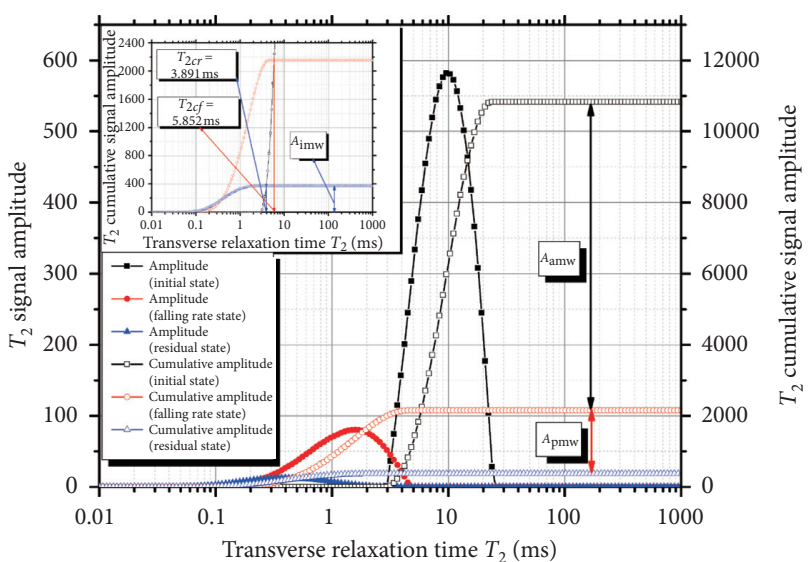

(b)

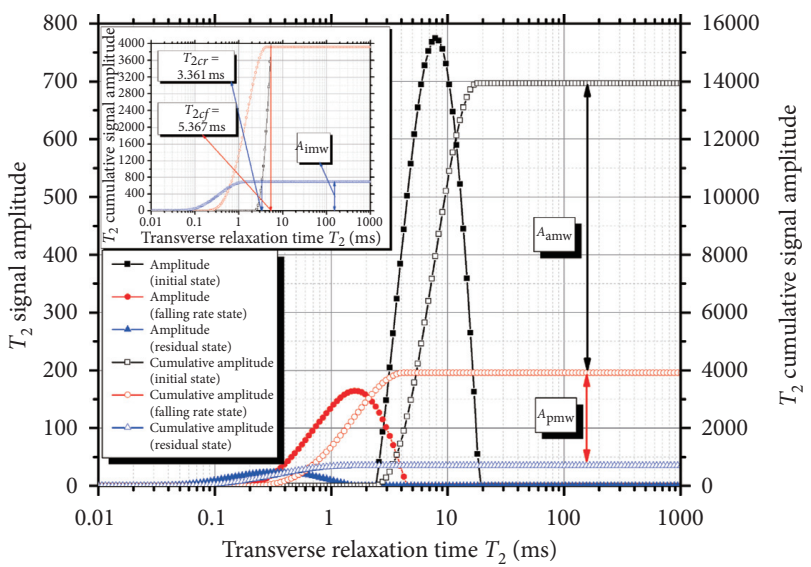

(d)

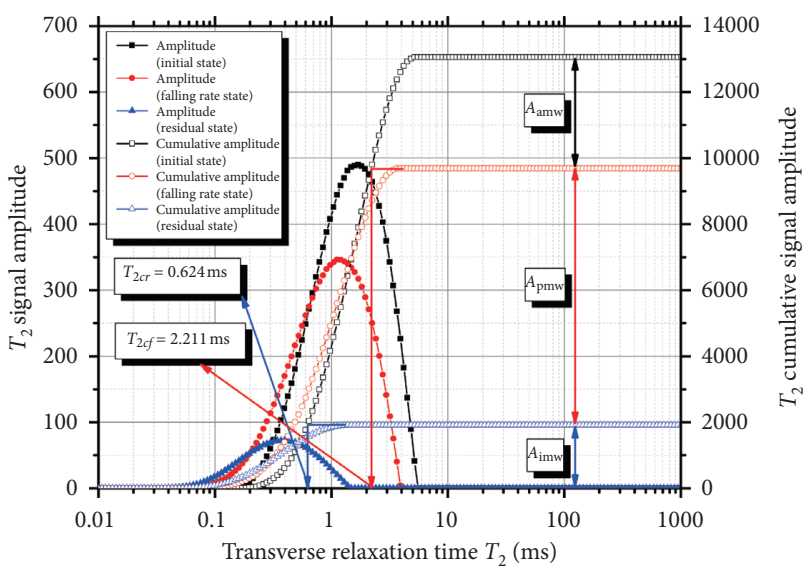

(f)

Figure 7: Continued. 


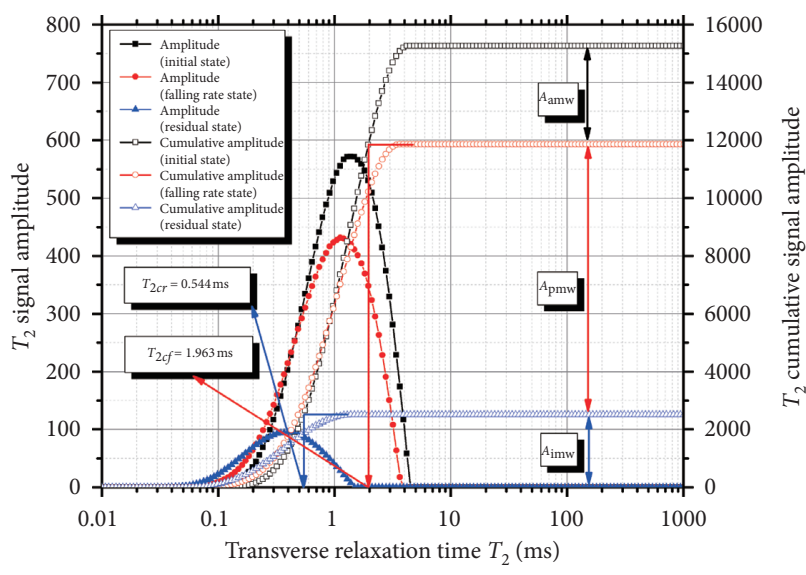

(g)

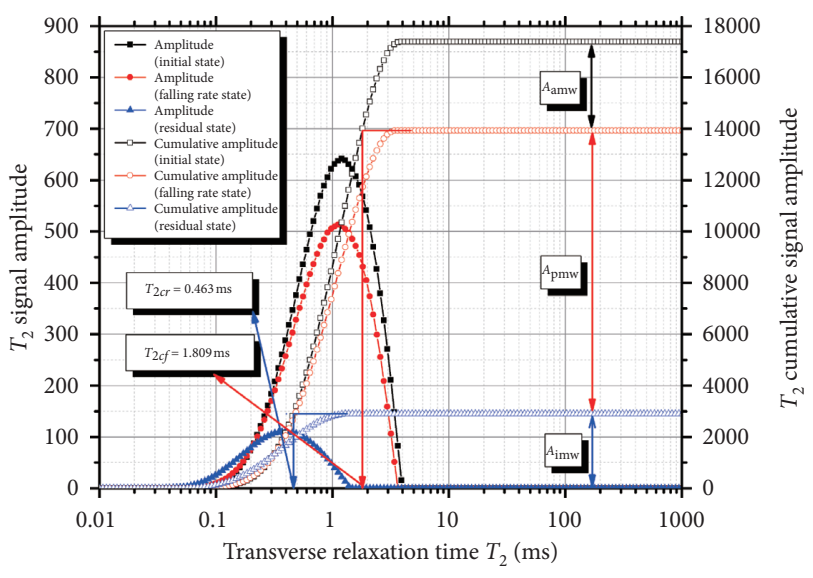

(h)

Figure 7: Double $T_{2}$ cut-offs of the eight artificial clayey soils: (a) K40, (b) K60, (c) K80, (d) K100, (e) M40, (f) M60, (g) M80, and (h) M100.

TABLe 3: $A_{t}, \varphi_{\mathrm{NMR}}, A_{\mathrm{imw}}, A_{\mathrm{pmw}}$, and $A_{\mathrm{amw}}$ values of the eight kinds of artificial clayey soil.

\begin{tabular}{lccccc}
\hline & $A_{t}$ & $\varphi_{\mathrm{NMR}}$ & $A_{\text {imw }}$ & $A_{\text {pmw }}$ & $A_{\mathrm{amw}}$ \\
\hline M40 & 11864.73 & 0.40843 & 1273.73 & 7253.32 & 3337.68 \\
M60 & 13051.19 & 0.44927 & 1909.46 & 7782.87 & 3358.86 \\
M80 & 15260.68 & 0.52533 & 2512.15 & 9353.37 & 3395.17 \\
M100 & 17385.43 & 0.59847 & 2896.94 & 11032.8 & 3455.69 \\
K40 & 9875.78 & 0.33996 & 213.38 & 938.06 & 8723.96 \\
K60 & 10826.21 & 0.37268 & 371.38 & 1282.31 & 8972.52 \\
K80 & 12407.74 & 0.42712 & 518.59 & 2314.89 & 9574.26 \\
K100 & 13937.11 & 0.47977 & 695.33 & 3219.66 & 10022.11 \\
\hline
\end{tabular}

increasing $\varphi_{\mathrm{NMR}}$ mainly because there were differences in the mineralogical compositions of the eight artificial clayey soils. For clayey soils consisting of the same mineral, $K_{\mathrm{TC}}$ decreased with decreasing $\varphi_{\mathrm{NMR}}$.

As shown in Figure 8, the relationships between $K_{\mathrm{TC}}$ and $\varphi_{\mathrm{NMR}}, A_{\mathrm{pmw}} / A_{\mathrm{amw}}$, and $A_{\mathrm{imw}} / A_{\mathrm{amw}}$ can be expressed by the following equations:

$$
\begin{aligned}
K_{\mathrm{TC}} & =0.027 \varphi_{\mathrm{NMR}}^{-8.337}, \\
K_{\mathrm{TC}} & =3.891\left(\frac{A_{\mathrm{pmw}}}{A_{\mathrm{amw}}}\right)^{-1.789}, \\
K_{\mathrm{TC}} & =0.751\left(\frac{A_{\mathrm{imw}}}{A_{\mathrm{amw}}}\right)^{-1.529} .
\end{aligned}
$$

The $R^{2}$ values of equations (12)-(14) were $0.927,0.984$, and 0.983 , respectively. On the basis of equations (11)-(14), the improved TC model could be further established. This model can be expressed by the following equation:

$$
K_{\mathrm{TC}}=0.546 \varphi_{\mathrm{NMR}}^{-3.051}\left(\frac{A_{\mathrm{pmw}}}{A_{\mathrm{amw}}}\right)^{-0.156}\left(\frac{A_{\mathrm{imw}}}{A_{\mathrm{amw}}}\right)^{-0.632} .
$$

Figure 9 presents a comparison of the predicted and measured permeability coefficients. All points are very close to the line $y=x$. This indicates that the improved TC model can be used to reliably predict the permeability coefficient of artificial clayey soil.

$R^{2}$, mean absolute error (MAE), and root-mean-square error (RMSE) are often used to evaluate the prediction capability of a predictive model. These parameters can be determined by the following equations:

$$
\begin{aligned}
R^{2} & =1-\frac{\sum_{i=1}^{N}\left(X_{\text {prei }}-X_{\text {meai }}\right)^{2}}{\sum_{i=1}^{N}\left(X_{\text {prei }}-\bar{X}_{\text {meai }}\right)^{2}}, \\
\text { MAE } & =\frac{1}{N} \sum_{i=1}^{N}\left|X_{\text {prei }}-X_{\text {meai }}\right|, \\
\text { RMSE } & =\sqrt{\frac{1}{N} \sum_{i=1}^{N}\left[X_{\text {prei }}-X_{\text {meai }}\right]^{2}},
\end{aligned}
$$

where $X_{\text {prei }}, X_{\text {meai }}$, and $\bar{X}_{\text {meai }}$ symbolize the predicted, measured, and mean measured values, respectively.

This improved TC model was proposed based on double $T_{2}$ cut-offs. The typical TC model based on a single $T_{2}$ cut-off for artificial clayey soil was established in our previous study [17]. The $R^{2}$, MAE, and RMSE values of the two models are listed in Table 4 and shown in Figure 10. As shown in Table 4, the $R^{2}$, MAE, and RMSE values of the improved TC model are $0.999,1.050$, and 1.370 , respectively. However, the corresponding values of the typical TC model are 0.957, 3.096 , and 3.828, respectively. It can be seen that the $R^{2}$ value of the improved TC model is bigger than that of the typical TC model. This suggests that the connection between the measured $K$ and predicted $K$ in the improved TC model is stronger than that in the typical TC model. In addition, the MAE and RMSE values of the improved TC model are much smaller than those of the typical TC model. This indicates that the error between the measured $K$ and predicted $K$ of the improved TC model is much smaller than that of the typical TC model. The prediction capability of the improved TC model is thus much higher than that of the typical TC model. 


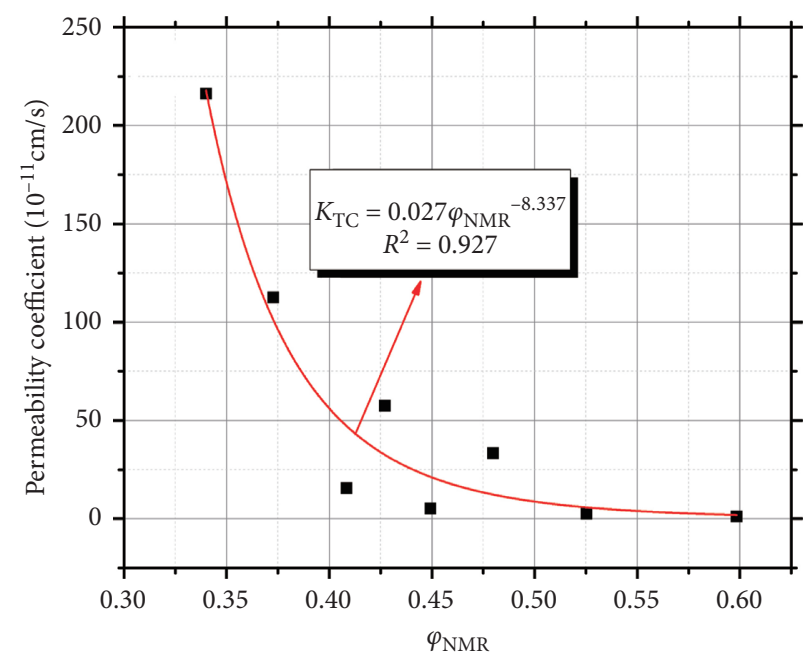

(a)

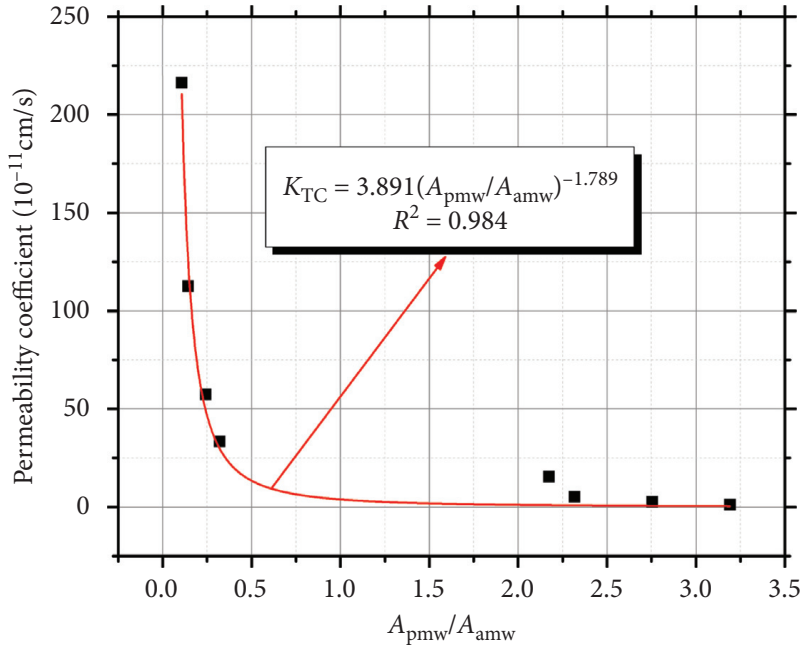

(b)

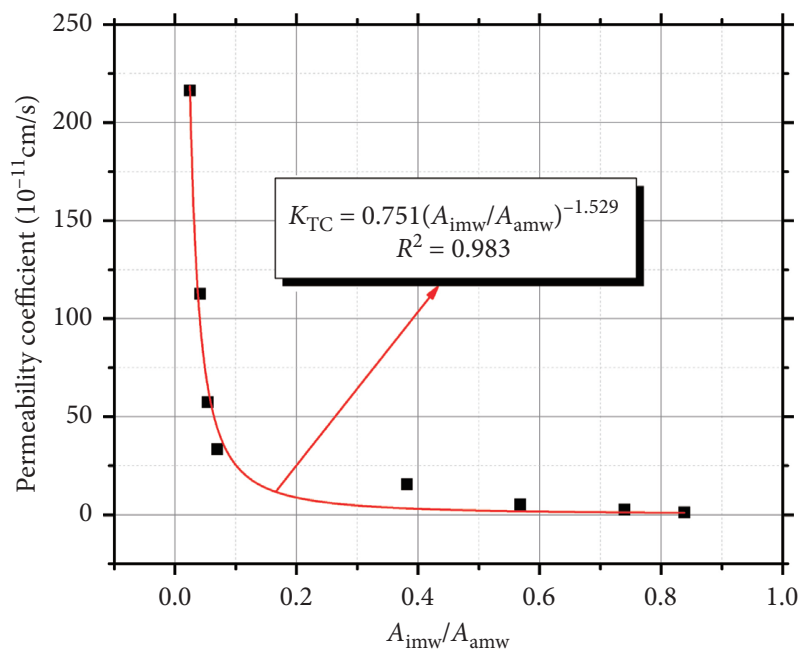

(c)

FIGURE 8: The relationships between $K_{\mathrm{TC}}$ and $\varphi_{\mathrm{NMR}}, A_{\mathrm{pmw}} / A_{\mathrm{amw}}$, and $A_{\mathrm{imw}} / A_{\mathrm{amw}}$ : (a) $\varphi_{\mathrm{NMR}}$, (b) $A_{\mathrm{pmw}} / A_{\mathrm{amw}}$, and (c) $A_{\mathrm{imw}} / A_{\mathrm{amw}}$.

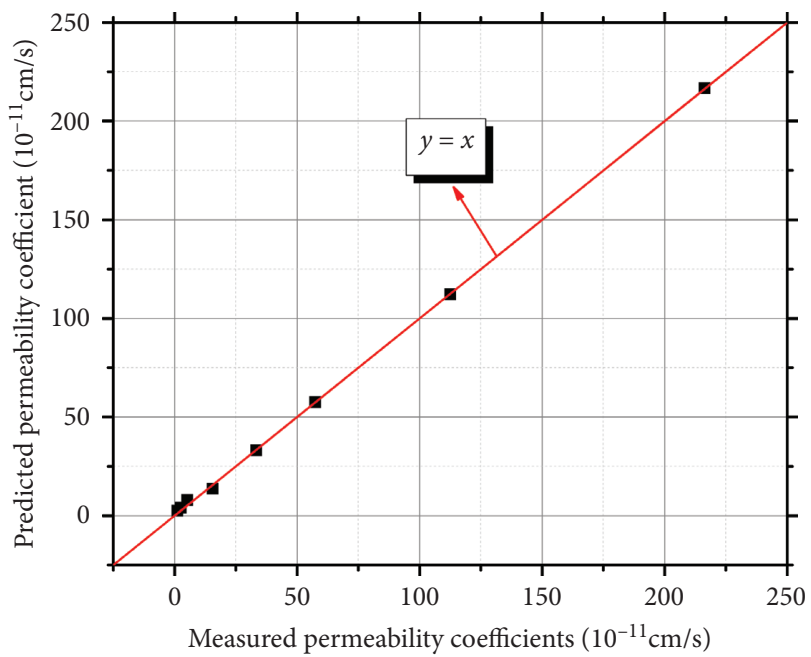

FIGURE 9: Comparison of the predicted and measured permeability coefficients.
TABLE 4: The determination coefficient $\left(R^{2}\right)$, mean absolute error (MAE), and root-mean-square error (RMSE) values of the improved Timur-Coates (TC) model and typical TC model.

\begin{tabular}{lccc}
\hline Model & $R^{2}$ & MAE & RMSE \\
\hline Improved TC model & 0.999 & 1.050 & 1.370 \\
Typical TC model & 0.957 & 3.096 & 3.828 \\
\hline
\end{tabular}

3.3. Determination of the Double $T_{2}$ Cut-Offs Based on Fractal Analysis. Before applying the improved TC model, it is necessary to determine the double $T_{2}$ cut-offs to classify the cumulative signal amplitudes of $T_{2}$ spectra corresponding to different kinds of water in artificial clayey soil. It takes a long time and great effort to determine the double $T_{2}$ cut-offs by evaporation tests. According to our previous study [17], the $\mathrm{T}_{2}$ cut-off can be determined by fractal analysis. There is a linear relationship between the $T_{2}$ cut-off and the fractal dimension $(D)$ of the $T_{2}$ spectrum of saturated artificial clayey soil. The $D$ value can then be used to determine the 


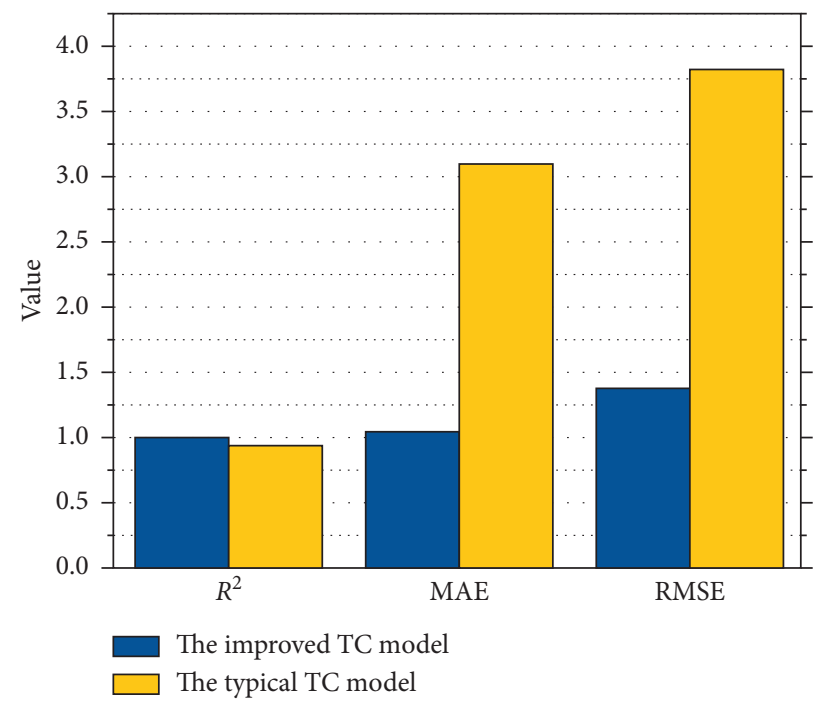

Figure 10: The $R^{2}$, MAE, and RMSE values of the improved and typical TC models.

TABle 5: The $D, T_{2 c r}$ and $T_{2 c f}$ values of the eight artificial clayey soils.

\begin{tabular}{lccccccrr}
\hline Artificial clayey soil & M40 & M60 & M80 & M100 & K40 & K60 & K80 & K100 \\
\hline$D$ & 2.605 & 2.573 & 2.535 & 2.505 & 2.447 & 2.406 & 2.354 & 2.303 \\
$T_{2 c r}$ & 0.679 & 0.624 & 0.544 & 0.463 & 4.468 & 3.891 & 3.736 & 3.361 \\
$T_{2 c f}$ & 2.799 & 2.211 & 1.963 & 1.809 & 6.136 & 5.852 & 5.686 & 5.367 \\
\hline
\end{tabular}

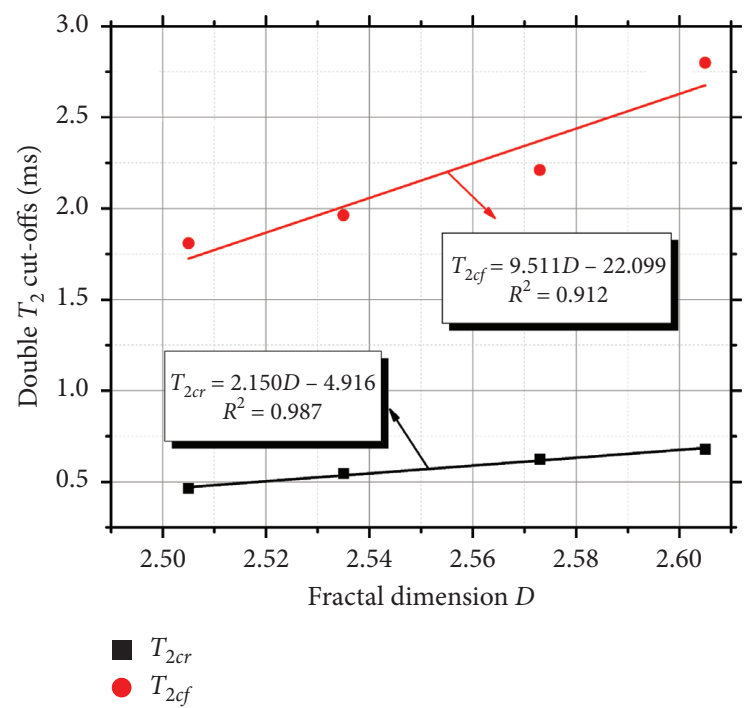

(a)

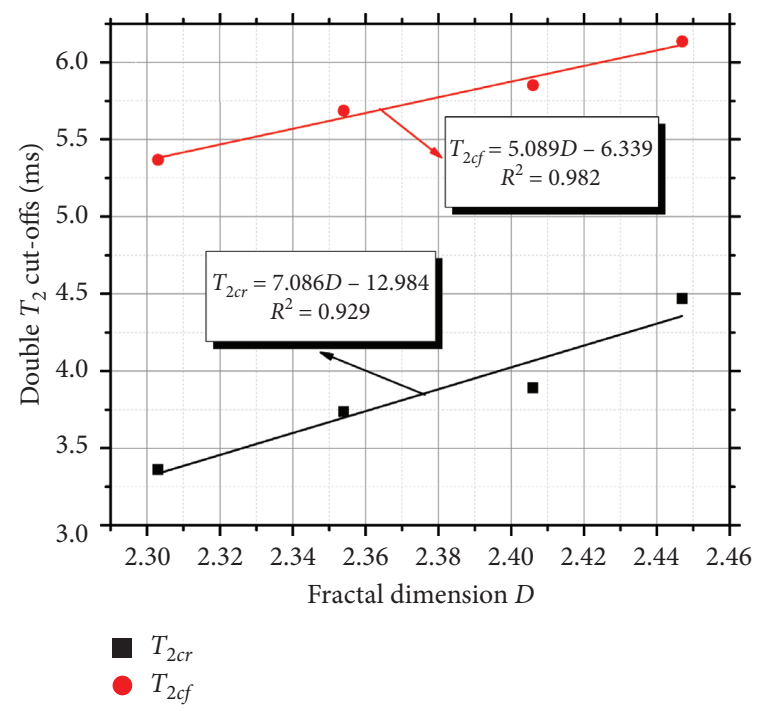

(b)

Figure 11: The relationships between the double $T_{2}$ cut-offs and fractal dimensions: (a) M-group and (b) K-group.

double $T_{2}$ cut-offs. It is noteworthy that the fractal dimensions were determined based on the $T_{2}$ spectra obtained from the results of the NMR tests. The pore size of an artificial clayey soil is proportional to $T_{2}$, so, actually, the fractal dimensions were determined according to the pore size distributions of the artificial clayey soil. So, the fractal dimensions in the manuscript were treated for space. The $D$,
$T_{2 c r}$, and $T_{2 c f}$ values of the eight artificial clayey soils are listed in Table 5. As shown in Table 5, a smaller fractal dimension was obtained for samples with higher clay content. Further, the fractal dimensions of the $M$ series were larger than those of the $K$ series. According to the relevant literature $[38,39]$, the probability density function of pore size can be written as follows: 


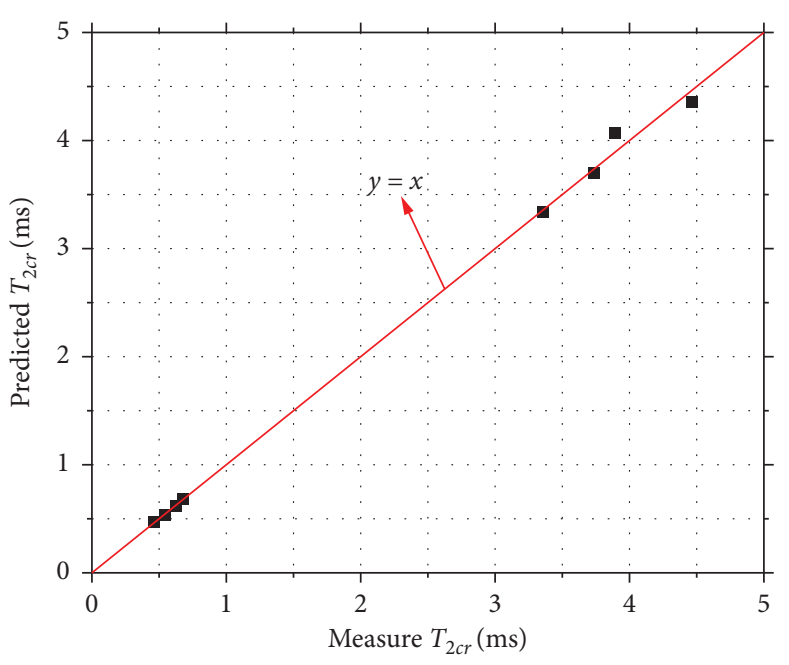

(a)

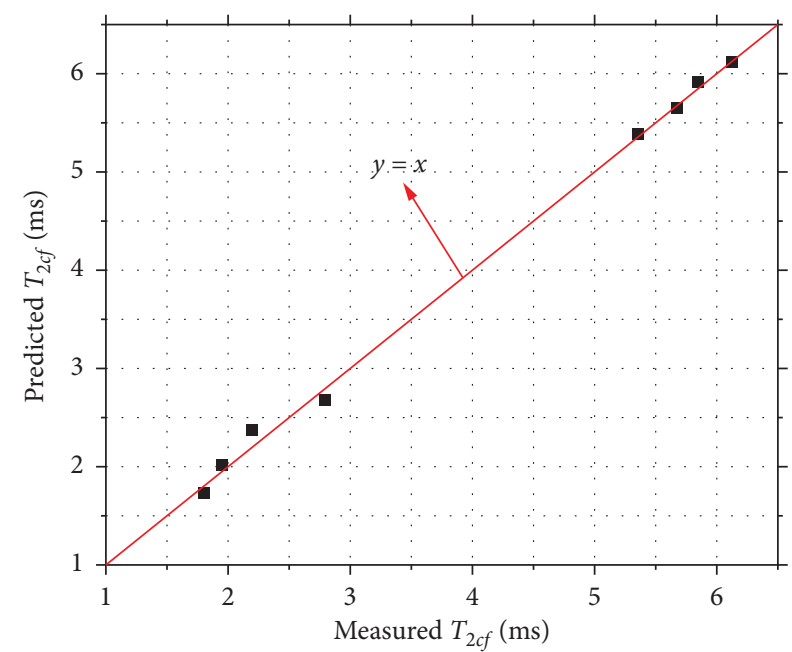

(b)

Figure 12: Comparison of the predicted and measured double $T_{2}$ cut-offs: (a) $T_{2 c r}$ and (b) $T_{2 c f}$.

$$
f(r)=c r^{-1-D} \text {, }
$$

where $c$ is constant. It can be concluded from equation (19) that the fractal dimension of artificial clayey soil decreases with increasing uniformity of the pore distribution. This indicates that the uniformity of artificial clayey soil with higher clay content is higher. For artificial clayey soil with the same clay content, the uniformity of the $M$ series was worse than that of the $K$ series.

The relationships between the double $T_{2}$ cut-offs and fractal dimensions are shown in Figure 11. As shown in Figure 11(a), the relationships between the double $T_{2}$ cutoffs and fractal dimensions of artificial clayey soil in the $M$ group can be expressed by the following equations:

$$
\begin{gathered}
T_{2 c r-m}=2.150 D-4.916 \\
T_{2 c f-m}=9.511 D-22.099 .
\end{gathered}
$$

As presented in Figure 11(b), the relationships between the double $T_{2}$ cut-offs and fractal dimensions of artificial clayey soil in the $K$-group can be expressed by the following equations:

$$
\begin{aligned}
& T_{2 c r-k}=7.086 D-12.984, \\
& T_{2 c f-k}=5.089 D-6.339 .
\end{aligned}
$$

The predicted double $T_{2}$ cut-offs of artificial clayey soil can be calculated by equations (20)-(23). A comparison between the predicted and measured double $T_{2}$ cut-offs is presented in Figure 12. The points in Figures 12(a) and 12(b) are very close to the line $y=x$; this indicates that the error between the predicted and measured double $T_{2}$ cut-offs is small.

The $R^{2}$, MAE, and RMSE values were also determined to evaluate the prediction accuracy of equations (20)-(23), and these values for the predictive equations are shown in
TABle 6: The $R^{2}$, MAE, and RMSE values of the predictive equations for the double $T_{2}$ cut-offs.

\begin{tabular}{lccc}
\hline Double $T_{2}$ cut-offs & $R^{2}$ & MAE & RMSE \\
\hline$T_{2 c r}$ & 0.998 & 0.0476 & 0.0753 \\
$T_{2 c f}$ & 0.998 & 0.0687 & 0.0835 \\
\hline
\end{tabular}

Table 6. From Figure 12 and Table 6, it can be seen that the prediction capability of the predictive equations for the double $T_{2}$ cut-offs is sufficient.

\section{Conclusions}

Evaporation and NMR tests were carried out on eight artificial clayey soils with different mineral compositions. On the basis of the results of tests and a discussion, the main conclusions are as follows:

(1) The $T_{2}$ total signal amplitude is proportional to the weight of distilled water in artificial clayey soil. During the evaporation process, the $T_{2}$ total signal amplitude decreased until it was stable. The decay rate of the $T_{2}$ total signal amplitude was constant at first and then decreased gradually to zero. Based on the different decay rates, the evaporation process can be divided into three stages: the constant rate stage, the falling rate stage, and the residual stage.

(2) Based on the three stages of the evaporation process, the water in artificial clayey soil can be classified into three categories: absolute movable water, partially movable water, and immovable water. Double $T_{2}$ cut-offs were also defined to distinguish the cumulative signal amplitudes in the $T_{2}$ spectrum corresponding to the different kinds of water.

(3) An improved TC model for predicting the permeability coefficient of artificial clayey soil was proposed. The improved and typical models were 
evaluated by determining their $R^{2}$, MAE, and RMSE values. The prediction accuracy of the improved model is much higher than that of the typical one.

(4) To simplify the prediction process, the relationships between the double $T_{2}$ cut-offs and the fractal dimension of the $T_{2}$ spectrum of saturated clayey soil were also established.

\section{Data Availability}

The data used to support the findings of this study have not been made available because the data also form part of an ongoing study (National Key Research and Development Program of China).

\section{Conflicts of Interest}

The authors declare no conflicts of interest.

\section{Acknowledgments}

This research was funded by the National Key Research and Development Program of China (Grant no. 2018YFB1600200).

\section{References}

[1] Y. Deng, Z. Wu, Y. Cui, S. Liu, and Q. Wang, "Sand fraction effect on hydro-mechanical behavior of sand-clay mixture," Applied Clay Science, vol. 135, pp. 355-361, 2017.

[2] Q. A. Al Rashid, H. M. Abuel-Naga, E.-C. Leong, Y. Lu, and H. Al Abadi, "Experimental-artificial intelligence approach for characterizing electrical resistivity of partially saturated clay liners," Applied Clay Science, vol. 156, pp. 1-10, 2018.

[3] T. Kozlowski and A. Ludynia, "Permeability coefficient of low permeable soils as a single-variable function of soil parameter," Water, vol. 11, no. 12, p. 20, 2019.

[4] L. L. Zeng, Z. S. Hong, Y. Q. Cai, and J. Han, "Change of hydraulic conductivity during compression of undisturbed and remolded clays," Applied Clay Science, vol. 51, no. 1-2, pp. 86-93, 2011.

[5] G. Mesri and R. E. Olson, "Mechanisms controlling the permeability of clays," Clays and Clay Minerals, vol. 19, no. 3, pp. 151-158, 1971.

[6] A. M. Samarasinghe, Y. Huang, and V. Drnevich, "Permeability and consolidation of normally consolidated soils," Journal of the Geotechnical Engineering Division, vol. 108, no. 6, pp. 835-850, 1982.

[7] B. Dolinar, "Predicting the hydraulic conductivity of saturated clays using plasticity-value correlations," Applied Clay Science, vol. 45, no. 1-2, pp. 90-94, 2009.

[8] G. Achari and R. Joshi, "A reexamination of the permeability index of clays: discussion," Canadian Geotechnical Journal, vol. 31, no. 1, pp. 140-141, 2011.

[9] K. Yamada, Y. Watabe, and K. Saitoh, "Hydraulic conductivity and compressibility of mixtures of nagoya clay with sand or bbntonite," Geotechnique (UK), vol. 61, no. 3, pp. 211-219, 2011.

[10] A. A. Behroozmand, K. Keating, and E. Auken, "A review of the principles and applications of the NMR technique for near-surface characterization," Surveys in Geophysics, vol. 36, no. 1, pp. 27-85, 2014.
[11] B. Kong, F. Xia, B. Yu, T. Xia, and Z. Ding, "Pore size changes in marine soft soil under various freezing conditions," Journal of Marine Science and Engineering, vol. 8, no. 3, p. 170, 2020.

[12] Z. Liu, D. Liu, Y. Cai, Y. Yao, Z. Pan, and Y. Zhou, "Application of nuclear magnetic resonance (NMR) in coalbed methane and shale reservoirs: a review," International Journal of Coal Geology, vol. 218, Article ID 103261, 2020.

[13] Y. Sun, C. Zhai, J. Z. Xu, Y. Z. Cong, L. Qin, and C. Zhao, "Characterisation and evolution of the full size range of pores and fractures in rocks under freeze-thaw conditions using nuclear magnetic resonance and three-dimensional X-ray microscopy,” Engineering Geology, vol. 271, p. 14, 2020.

[14] Y. Yao, D. Liu, J. Liu, and S. Xie, "Assessing the water migration and permeability of large intact bituminous and anthracite coals using NMR relaxation spectrometry," Transport in Porous Media, vol. 107, no. 2, pp. 527-542, 2015.

[15] A. Li, W. Ding, R. Wang et al., "Petrophysical characterization of shale reservoir based on nuclear magnetic resonance (NMR) experiment: a case study of lower cambrian Qiongzhusi formation in eastern Yunnan province, South China," Journal of Natural Gas Science and Engineering, vol. 37, pp. 29-38, 2017.

[16] R. Rezaee, A. Saeedi, and B. Clennell, "Tight gas sands permeability estimation from mercury injection capillary pressure and nuclear magnetic resonance data," Journal of Petroleum Science and Engineering, vol. 88-89, pp. 92-99, 2012.

[17] Z. Lu, A. Sha, and W. Wang, "Permeability evaluation of clayquartz mixtures based on low-field NMR and fractal analysis," Applied Sciences, vol. 10, no. 5, p. 1585, 2020.

[18] S. Haber-Pohlmeier, S. Stapf, and A. Pohlmeier, "NMR fast field cycling relaxometry of unsaturated soils," Applied Magnetic Resonance, vol. 45, no. 10, pp. 1099-1115, 2014.

[19] C. Buchmann, M. Meyer, and G. E. Schaumann, "Characterization of wet aggregate stability of soils by $\mathrm{H}-\mathrm{NMR}$ relaxometry," Magnetic Resonance in Chemistry, vol. 53, no. 9, pp. 694-703, 2015.

[20] M. Meyer, C. Buchmann, and G. E. Schaumann, "Determination of quantitative pore-size distribution of soils with $1 \mathrm{H}$ NMR relaxometry," European Journal of Soil Science, vol. 69, no. 3, pp. 393-406, 2018.

[21] H. Tian, C. Wei, H. Wei, and J. Zhou, "Freezing and thawing characteristics of frozen soils: bound water content and hysteresis phenomenon," Cold Regions Science and Technology, vol. 103, pp. 74-81, 2014.

[22] L. R. Stingaciu, A. Pohlmeier, P. Blümler et al., "Characterization of unsaturated porous media by high-field and lowfield NMR relaxometry," Water Resources Research, vol. 45, no. 8, p. 8412, 2009.

[23] F. Jaeger, S. Bowe, H. Van As, and G. E. Schaumann, "Evaluation of $1 \mathrm{H}$ NMR relaxometry for the assessment of pore-size distribution in soil samples," European Journal of Soil Science, vol. 60, no. 6, pp. 1052-1064, 2009.

[24] K. Keating and S. Falzone, "Relating nuclear magnetic resonance relaxation time distributions to void-size distributions for unconsolidated sand packs," Geophysics, vol. 78, no. 6, pp. D461-D472, 2013.

[25] H. Tian, C. Wei, and L. Tan, "Effect of freezing-thawing cycles on the microstructure of soils: a two-dimensional NMR relaxation analysis," Cold Regions Science and Technology, vol. 158, pp. 106-116, 2019.

[26] L. Kong, H. M. Sayem, and H. Tian, "Influence of dryingwetting cycles on soil-water characteristic curve of undisturbed granite residual soils and microstructure mechanism 
by nuclear magnetic resonance (NMR) spin-spin relaxation time $\left(T_{2}\right)$ relaxometry," Canadian Geotechnical Journal, vol. 55, no. 2, pp. 208-216, 2018.

[27] Y.-T. Huang, Z.-Y. Hseu, and H.-C. Hsi, "Influences of thermal decontamination on mercury removal, soil properties, and repartitioning of coexisting heavy metals," Chemosphere, vol. 84, no. 9, pp. 1244-1249, 2011.

[28] Y. Wang, S. Lu, T. Ren, and B. Li, "Bound water content of airdry soils measured by thermal analysis," Soil Science Society of America Journal, vol. 75, no. 2, pp. 481-487, 2011.

[29] J. Kucerik, D. Tokarski, M. S. Demyan, I. Merbach, and C. Siewert, "Linking soil organic matter thermal stability with contents of clay, bound water, organic carbon and nitrogen," Geoderma, vol. 316, pp. 38-46, 2018.

[30] S. Li, C. Wang, X. Zhang, L. Zou, and Z. Dai, "Classification and characterization of bound water in marine mucky silty clay," Journal of Soils and Sediments, vol. 19, no. 5, pp. 2509-2519, 2019.

[31] I. Menapace, E. Masad, G. Papavassiliou, and E. Kassem, "Evaluation of ageing in asphalt cores using low-field nuclear magnetic resonance," International Journal of Pavement Engineering, vol. 17, no. 10, pp. 847-860, 2016.

[32] L. R. Stingaciu, L. Weihermüller, S. Haber-Pohlmeier, S. Stapf, H. Vereecken, and A. Pohlmeier, "Determination of pore size distribution and hydraulic properties using nuclear magnetic resonance relaxometry: a comparative study of laboratory methods," Water Resources Research, vol. 46, no. 11, 2010.

[33] Y.-Q. Song, L. Venkataramanan, M. D. Hürlimann, M. Flaum, P. Frulla, and C. Straley, " $T_{1}-T_{2}$ correlation spectra obtained using a fast two-dimensional Laplace inversion," Journal of Magnetic Resonance, vol. 154, no. 2, pp. 261-268, 2002.

[34] K. A. Dines and R. J. Lytle, "Computerized geophysical tomography," Proceedings of the IEEE, vol. 67, no. 7, pp. 1065-1073, 1979.

[35] M. N. Testamanti and R. Rezaee, "Determination of NMR $T_{2}$ cut-off for clay bound water in shales: a case study of Carynginia formation, Perth Basin, Western Australia," Journal of Petroleum Science and Engineering, vol. 149, pp. 497-503, 2017.

[36] C. S. Tang, B. Shi, C. Liu, W. B. Suo, and L. Gao, "Experimental characterization of shrinkage and desiccation cracking in thin clay layer," Applied Clay Science, vol. 52, no. 1-2, pp. 69-77, 2011.

[37] W. Jiang, D. Yuan, J. Shan, W. Ye, H. Lu, and A. Sha, "Experimental study of the performance of porous ultra-thin asphalt overlay," International Journal of Pavement Engineering, pp. 1-13, 2020.

[38] G. Tao and J. Zhang, "Two categories of fractal models of rock and soil expressing volume and size-distribution of pores and grains," Science Bulletin, vol. 54, no. 23, pp. 4458-4467, 2009.

[39] G. L. Tao, Y. Chen, L. W. Kong, H. L. Xiao, Q. S. Chen, and Y. X. Xia, "A simple fractal-based model for soil-water characteristic curves incorporating effects of initial void ratios," Energies, vol. 11, no. 6, p. 20, 2018. 